DOI 10.3233/JAD-179009

IOS Press

\title{
Erratum
}

\section{Obituary: The Life and Science of Allen Roses' Lives On}

Jamie Talan

[Journal of Alzheimer's Disease 60(3), 2017, 747-749, DOI 10.3233/JAD-170820]

https://content.iospress.com/articles/journal-of-alzheimers-disease/jad170820

Please find below the photo of Dr. Allen Roses:

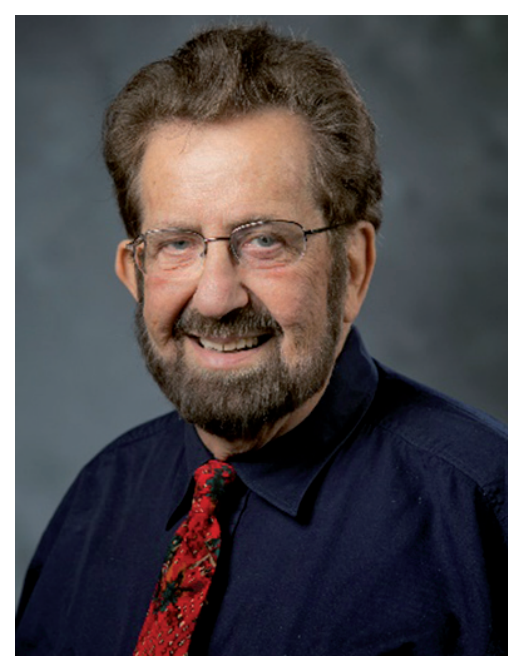

